\title{
Modeling and prediction of a simplified seizure mechanism occurring in conrod bearings
}

\author{
JEAN-LOUis LigieR ${ }^{\mathrm{a}}$ AND LAURENT DUtFoy \\ Powertrain division, RENAULT SAS, 67 rue des bons raisins, 92508 Rueil-Malmaison, France
}

Received 11 October 2010, Accepted 8 April 2011

\begin{abstract}
The paper concerns the transient thermal behavior of a conrod bearing in an automotive engine subjected to various running conditions. The thermal model is oil shear and contact friction heat generation components. The first part of the paper covers some of the industrial and scientific aspects related to bearings seizure, and emphasizes the importance of removing this failure mechanism as early as the incipient development stages of new automotive engines. The second part concerns several of the broad array of factors that approximate a seizure mechanism. In the third and final part, the mathematical model for conrod bearings seizure is revealed. The objective of the paper is to confirm the conrod seizure model's utility, complementary with more refined approaches such as the thermo-elasto-hydrodynamic approach.
\end{abstract}

Key words: Crankpin / seizure / mixed lubrication / heat transfer / Maple

Résumé - Modélisation et prédiction d'un mécanisme simplifié de grippage d'un palier de tête de bielle. L'article traite de la simulation thermique transitoire d'un palier de tête de bielle de moteur automobile soumis à différentes conditions de fonctionnement. La modélisation thermique est simplifiée mais toutefois en privilégiant la physique de certains phénomènes en vue de prédire le grippage induit par les échauffements générés par le cisaillement d'huile et les contacts frottants. Dans un premier temps, un éclairage est donné sur la problématique industrielle et scientifique des problèmes de grippage survenant lors du développement d'un nouveau moteur. À ce titre, l'accent est mis sur le caractère multidisciplinaire des aspects à considérer. Dans un second temps, on s'attache à décrire les aspects physiques prédominants dans le mécanisme de grippage considéré. Enfin dans un troisième temps, il s'agit de détailler les différentes mises en équations qui ont permis d'appréhender de façon réaliste des phénomènes de grippage observés sur des paliers de moteurs thermiques. L'objectif final vise à mettre en relief l'aide apportée par ce type d'approche et la complémentarité de celle-ci avec des approches plus élaborées comme de la thermo-élastohydrodynamique.

Mots clés : Maneton / grippage / lubrification mixte / transfert de chaleur / Maple

\section{Introduction}

To start an analysis dedicated to seizure, it is useful to recall the definition of the term. In "Larousse", respectively "Littre" French dictionaries, one finds as definition for seizure: "warm-up and adhesion by lack lubricant", respectively "effect that two metallic surfaces produce on themselves when rubbing one against the other one". To report accurately the failures met in the automotive engine bearings, it is preferable to define seizure as a divergent thermal process.

The thermal divergence originates from a sudden unbalance between the evacuated thermal power, and the

a Corresponding author: jean-louis.ligier@renault.com power generated through friction, the latter exceeding the former. This shortage in power balance can have multiple causes, or initiators, such as the increase of friction factor by the adhesion of materials in contact, an inadequate clearance, or a deficient bearing cooling. As the potential initiators are both numerous and moreover can be combined together, a seizure simulation dedicated to conrod bearings requires thus that these initiators be firstly acknowledged. To underline the difficulty for the design engineers, it is worth mentioning that the majority of lubrication commercial codes does not provide seizure simulation or seizure risk analysis modules.

In the field of automotive internal combustion engines (ICE), the frequency of bearings seizure during new 


\section{Nomenclature}

\begin{tabular}{|c|c|}
\hline$\alpha_{\mathrm{bi}}$ & Thermal expansion coefficient of the conrod \\
\hline$\alpha_{\mathrm{h}}$ & Thermal expansion coefficient of the oil \\
\hline$\alpha_{\text {cish }}$ & Ratio of power absorbed between an adiabatic bearing and a realistic bearing \\
\hline$\alpha_{\mathrm{ma}}$ & Thermal expansion coefficient of the crankpin \\
\hline$\beta$ & Correlation coefficient \\
\hline$\Delta$ & Distance operator \\
\hline$\varepsilon_{x c}$ & Ratio of equivalent eccentricity \\
\hline$\zeta$ & Angular position in the conrod bearing \\
\hline$\theta_{0}$ & Reference temperature \\
\hline$\theta_{\mathrm{ad}}$ & Temperature of the oil in an adiabatic bearing \\
\hline$\theta_{\text {ali }}$ & Oil temperature supplying the crankpin \\
\hline$\theta_{\text {alimax }}$ & Max temperature supplying the crankpin \\
\hline$\theta_{\text {alimin }}$ & Min temperature supplying the crankpin \\
\hline$\theta_{\mathrm{fpi}}$ & Temperature of the oil having cooled the piston \\
\hline$\theta_{\mathrm{mel}}$ & Melting temperature of the overlay \\
\hline$\theta_{i}$ & Mean temperature of the node $i$ \\
\hline$\theta_{\text {pis }}$ & Mean temperature of the piston \\
\hline$\theta_{\mathrm{s}}$ & Temperature of contact surface \\
\hline$\theta_{\text {st }}$ & Temperature of the oil in cooled bearing \\
\hline$\lambda_{\mathrm{i}}$ & Thermal conductivity of the element $\mathrm{i}$ of the nodal mesh \\
\hline$\lambda_{\text {oil }}$ & Thermal conductivity of the oil \\
\hline$\mu(\theta)$ & Dynamic viscosity, Mac Coull's and Walther relationship [6] \\
\hline$\nu$ & Poisson's ratio of the connecting rod \\
\hline$\phi_{a}$ & Heat flow in the shaft \\
\hline$\phi_{c}$ & Heat flow in the bearing \\
\hline$\phi_{i}$ & Heat flow in the node $i$ \\
\hline$\varphi_{0}$ & Friction factor \\
\hline$\phi\left(H_{\mathrm{c}}, \theta_{\text {fus }}, \theta_{\mathrm{s}}\right)$ & $\begin{array}{l}\text { Friction factor varying with respect to hardness, temperature, the material } \\
\text { and its ability to melt. }\end{array}$ \\
\hline$\rho_{0}$ & Reference oil density \\
\hline$\rho(\theta)$ & Density of the oil according to the temperature $\theta$ \\
\hline$\omega$ & Angular speed of the shaft \\
\hline$\xi$ & Coefficient of pressure loss in the piston jet \\
\hline$\psi(\zeta)$ & Filling ratio in the oil film \\
\hline$a_{0}$ & Constant in the Graetz's relationship \\
\hline$b_{\mathrm{a}}$ & Thermal effusivity of the shaft $=\sqrt{\lambda_{\text {shaft }} \rho_{\text {shaft }} C \mathrm{p}_{\text {shaft }}}$ \\
\hline$b_{\mathrm{c}}$ & Thermal effusivity of the bearing surface material \\
\hline $\mathrm{Cp}$ & Specific heat of the piston \\
\hline$C \mathrm{p}_{\mathrm{h}}$ & Specific heat of the oil \\
\hline$C \mathrm{p}_{\mathrm{i}}$ & Specific heat of the node $i$ \\
\hline$c, c_{0}, c_{1}$ & Constants \\
\hline$D_{\text {jet }}$ & Jet diameter \\
\hline$d$ & Diameter of the oil drilling in the crankshaft \\
\hline$E_{\text {ad }}$ & Thermal power due to oil shear in an adiabatic bearing \\
\hline$E_{\text {st }}$ & Thermal power due to oil shear in a realistic bearing \\
\hline$e_{\text {cis }}$ & Shear oil film thickness \\
\hline$e_{\mathrm{pf}}$ & Matrix of the oil film thickness with respect to the speed and to the oil supply temperature \\
\hline $\mathrm{e}_{\mathrm{pi}}$ & Thickness of thermal conduction for the element $i$ \\
\hline $\bar{e}(\zeta, t)$ & Mean oil film thickness in the bearing width (calculated in EHD) \\
\hline$H_{\mathrm{c}}$ & Bearing surface hardness \\
\hline$h_{0}$ & Heat transfer coefficient of reference \\
\hline$h_{\mathrm{a}}$ & Heat transfer coefficient of the crankshaft \\
\hline$h_{\mathrm{b}}$ & Heat transfer coefficient for the conrod \\
\hline$h_{\text {eau }}$ & Heat transfer coefficient between the piston and the cooling circuit \\
\hline$h_{\mathrm{eq}}$ & Equivalent heat transfer coefficient \\
\hline$h_{i}$ & Heat transfer coefficient for the node $i$ \\
\hline$h_{\text {Pis }}$ & Heat transfer coefficient between the piston and the oil \\
\hline$J_{\mathrm{r}}$ & Radial bearing clearance \\
\hline$J_{\operatorname{rmax}}$ & Max radial clearance \\
\hline
\end{tabular}




\begin{tabular}{|c|c|}
\hline$J_{\text {rmin }}$ & Min radial clearance \\
\hline$k_{0}$ & Coefficient of thermal power through the piston \\
\hline$L$ & Length of the crankshaft drilling \\
\hline $\mathrm{LF}$ & Circumferential length of the oil film \\
\hline $\mathrm{Mp}$ & Mass of the piston \\
\hline$m_{i}$ & Mass of the node $i$ \\
\hline$N^{i}$ & Rotation speed for the condition $i$ (rev/min) \\
\hline$N_{\max }$ & Max rotation speed \\
\hline$N_{\min }$ & Min rotation speed \\
\hline$N_{\text {ref }}$ & Rotation speed reference \\
\hline$N u$ & Nusselt's number in the crankshaft drilling \\
\hline $\bar{N} u$ & Mean Nusselt's number \\
\hline$P_{0}, P_{1}, P_{2}$ & Polynom coefficient \\
\hline$P_{\text {ali }}$ & Pump pressure according to the speed and to the temperature \\
\hline$P_{\mathrm{c}}$ & Contact pressure \\
\hline$P_{n}^{\mathrm{bi}}$ & Polynom of degree $n$ for radial temperature variation in the conrod \\
\hline$P_{m}^{\mathrm{ma}}$ & Polynom of degree $m$ for the radial temperature variation in crankpin \\
\hline$P_{\text {mot }}$ & Engine power \\
\hline $\operatorname{Pr}$ & Prandtl's number \\
\hline$P V_{\mathrm{c}}$ & Matrix of average contact PV with respect to space and time \\
\hline$\overline{P V_{\mathrm{c}}}(\zeta, t)$ & Average contact $\mathrm{PV}$ in the bearing width \\
\hline$R_{0}$ & Crankpin radius \\
\hline$R_{1}$ & Mean external big end radius \\
\hline$R_{\text {gir }}$ & Gyration radius \\
\hline$R e_{\mathrm{d}}$ & Reynolds number in the crankshaft drilling \\
\hline$r$ & Radial coordinate \\
\hline$S_{\text {eau }}$ & Piston surface affected by the cooling circuit \\
\hline$S_{i}$ & Heat transfer surface \\
\hline$S_{\text {Pis }}$ & Piston cooling surface \\
\hline$T_{\mathrm{bi}}$ & Mean big end temperature \\
\hline$T_{\mathrm{ma}}$ & Mean crankpin temperature \\
\hline$t$ & Time variable \\
\hline$U_{\mathrm{r}}^{\mathrm{bi}}$ & Radial displacement of the big end \\
\hline$U_{\mathrm{r}}^{\mathrm{ma}}$ & Radial displacement of the crankpin \\
\hline$V$ & Relative linear speed between the surfaces \\
\hline$x$ & Circumferential coordinate \\
\hline$Y_{\mathrm{sh}}$ & Shear strength \\
\hline
\end{tabular}

engines development has increased during the last decades. This increase results from:

- the "downsizing" of new engines in order to reduce their consumption. It consists in using an engine in specific running conditions to increase efficiency. Therefore, higher temperatures and superior engine loads;

- the increase of the maximum gas pressure to raise engine power and comply with emission regulations;

- the decrease in size and mass of engine components to reduce the $\mathrm{CO}_{2}$ emissions. As a consequence, the minimum oil film thickness is diminished for hydrodynamic bearings;

- starting with 2011, the use of antifriction materials containing lead is prohibited. Unfortunately, lead remains one of the best anti-seizure materials for its strong ductility, low melting point, very low solubility with various materials, nigh latent heat of liquefaction and high viscosity.

To cope with these evolutions and their associated risks, it is necessary to upgrade the simulation tools. Today, most design engineering departments have tools, more or less accurate to estimate risks in fatigue, wear or cavitation. On the other hand, seldom these departments have tools for evaluating the risks of seizure.

During a new engine development, the destruction of one of the prototypes and the delay costs associated to its destruction are around several million Euros. Hence, it is very important to reduce the seizure risk starting with the early design stages.

In the race to shorten development time, it is no longer acceptable to guarantee reliability only at the latest, or validation, stages in engine design. The current analysis is aimed to assess seizure risks at the first design stages of new engines.

Concerning the physics, some of the main difficulties inherent with the modeling and prediction of seizure are:

- the instability of this phenomenon;

- the broad array of factors influencing seizure;

- the variety of initiators, which can lead to this mode of failure;

- the difficulty of "a posteriori" seizure analysis for confirming the failure's root cause. 


\subsection{Instability of seizure}

It is almost impossible to identify exactly the circumstances of seizure triggering in engine bearings. The seizure behavior is rather close to the buckling behavior structures. A small disturbance of a lubricant particle, a pressure drop or a damage of the bearing surfaces can trigger a seizure process.

When it is not required to get an answer within the time domain, the robustness with respect to seizure can be perceived as the capacity of a bearing to absorb additional heat, with respect to a nominal heat, without leading failing.

\subsection{The broad array of factors influencing seizure}

The main difficulties arising, whilst characterizing seizure are connected to the broad range of factors which interact together to cause seizure. It requires a multidisciplinary approach to model the failure mechanism. Some important factors which are sometime neglected, are:

- the geometrical irregularities including: the noncircularity of the bearing, the possible step at the joint faces, or the surface defects. Unfortunately, the latter ones combine also problems of roughness, waviness, lobes or shape defects that independently influence the seizure risk;

- the realistic description of heat interaction surfaces. Values of contact pressure-velocity $(P V)$ parameter higher than several MPa.m.s ${ }^{-1}$ can exist for very short time frames $(\ll 1 \mathrm{~s})$;

- the heat transfer with the environment, in particular the crankshaft webs and conrods with the oil falling from the piston.

\subsection{Variety of initiators (causes) for seizure}

Obviously, it is almost impossible to identify all causes or initiators leading to seizure. However, identifying the main sources enables one to model them and assess their influence on seizure.

\section{4 “A posteriori” analysis}

During "a posteriori" analysis of an engine failure under seizure, it is often difficult to determine the root cause of the problem. Figure 1 shows a conrod and bearing set after seizure occurred.

Simply by examining Figure 1 it is impossible to identify the root an over-speed, a material quality problem, a conrod bolt defect, an abnormal combustion pressure, a fatigue problem or nonconformity of the surfaces lead to seizure?

To end with, the authors acknowledge some of the already existing models of seizure phenomena. Among the main approaches, the works of Buzescu, Burton, Fillon,
Monmousseau, Pascovici [1-4] stand out. These studies are mainly related to turbine bearings. The physical phenomena taken into account are thermal expansion and thermal equilibrium. However, the conrod bearing is not often approached.

\section{Modeling}

To simplify the analysis, only the big end bearing, assumed to be correctly supplied with oil, is studied. The engine is assumed to operate in the most severe conditions with respect to the bearing.

Therefore, for a given speed and very low engine load, the oil supply temperature will be maximum and the bearing loading corresponds to the most severe conditions in terms of seizure, as presented in the following sub-sections.

\subsection{Overview}

As seen during Formula 1 Grand Prix races, seizure of engine bearings is sometimes very rough. To get the best numerical approximations of the temperature evolution in time, the unsteady heat transfers in the bearing are approached with a nodal method which is detailed in Section 2.4. For all equations described below, it is assumed that the system is characterized by symmetry of revolution. It involves neglecting that in certain running conditions; the thermal flows can be localized on the cap or on the body of the conrod. Therefore, these flows can be more intense than those estimated through this simplification.

The overview diagram, Figure 2, shows the main modules of the simulation tool that has been developed. As it appears, three main blocks or modules form the simulation core. The first loop of iteration is related to the variation of bearing clearance according to the relative thermal expansion of the crankpin with respect to the conrod. The second loop is based on an advancement variable, for example the time or the speed. An additional iteration loop can be added to check for clearance or oil supply temperature values that lead to seizure.

As the thermal expansion governs the seizure mechanism in the current modeling, its equation is described below. It is considered that the radial temperature fields in the conrod and the crankpin follow the relationships:

$$
T_{\mathrm{bi}}(r)=P_{n}^{\mathrm{bi}}(r) \quad \text { and } \quad T_{\mathrm{ma}}(r)=P_{m}^{\mathrm{ma}}(r)
$$

with $P_{\mathrm{bi}}$ and $P_{\mathrm{ma}}$ polynomials of degree $n$ and $m$ "fitted" with the mathematical software Maple, and the discretized temperature nodes of the nodal network describing the conrod and the crankpin. The radial clearance evolution, $\Delta J r$, is monitored through relationship [5]:

$$
\Delta J_{\mathrm{r}}=U_{\mathrm{r}}^{\mathrm{bi}}-U_{\mathrm{r}}^{\mathrm{ma}}
$$

with

$$
U_{\mathrm{r}}^{\mathrm{ma}}=\frac{2 \alpha_{\mathrm{ma}}}{R_{0}} \int_{0}^{R_{0}} r T_{\mathrm{ma}}(r) \mathrm{d} r
$$




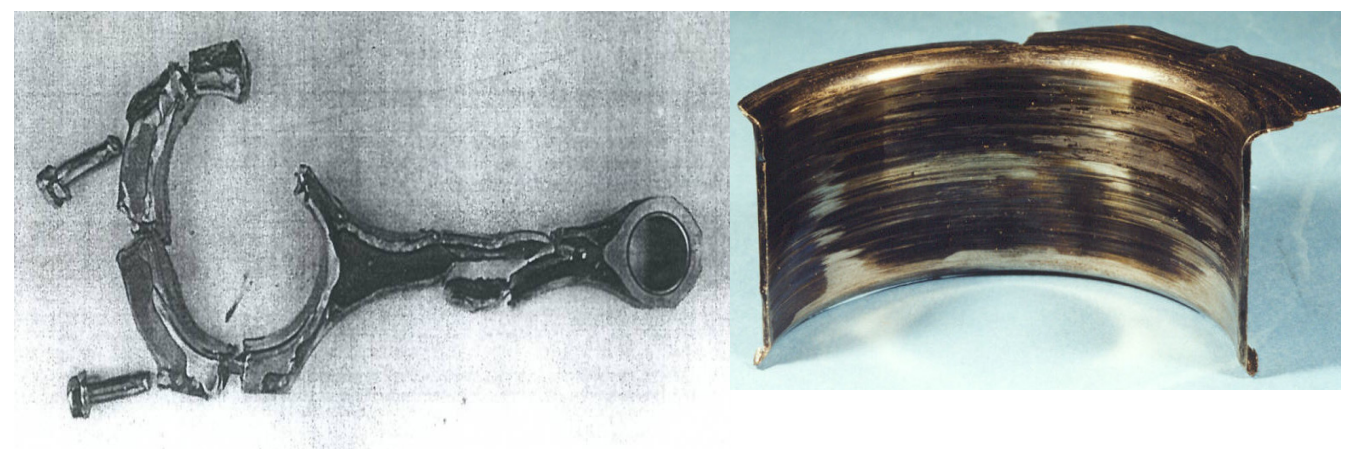

Fig. 1. Conrod and bearing after seizure.

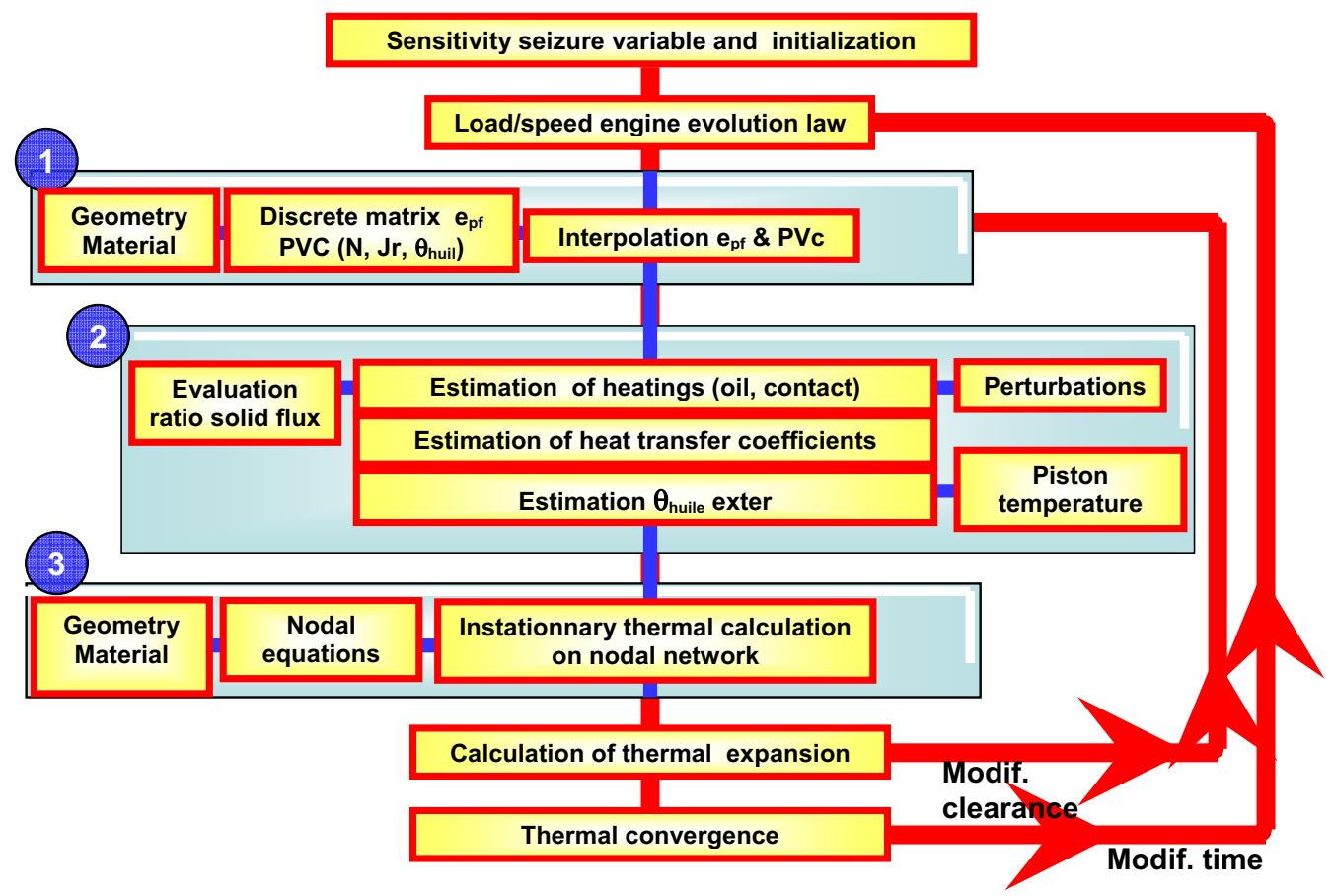

Fig. 2. Overview diagram of calculation.

and

$$
U_{\mathrm{r}}^{\mathrm{bi}}=\frac{(1+\nu) \alpha_{\mathrm{bi}}\left(R_{1}^{2}+R_{0}^{2}(1-2 \nu)\right)}{(1-\nu) R_{0}\left(R_{1}^{2}-R_{0}^{2}\right)} \int_{R_{0}}^{R_{1}} r T_{\mathrm{bi}}(r) \mathrm{d} r
$$

\subsection{Module "1": Oil film thickness module}

The module defines for a particular bearing geometry and material, for various running speeds, clearances and oil supply temperatures the following:

- A certain average film thickness, $e_{\mathrm{pf}}$, generating heat though viscous oil shearing in Petroff's bearing with eccentricity [6]. This has the same size and the same dissipated power as the realistic bearing.

- A certain value of contact $P V, P V_{\mathrm{c}}$ which is the product of the contact pressure $P_{\mathrm{c}}$ and the speed $V$. This quantity multiplied by the friction factor $\varphi$, between the two surfaces will be the heat generated by the interaction of the opposing surfaces (crankpin/bearing).

$$
e_{\mathrm{pf}}\left(N^{i}, J_{\mathrm{r}}^{i}, \theta_{\mathrm{ali}}^{i}\right)=\sqrt{\left(J_{\mathrm{r}}^{i}\right)^{2}-\left(\frac{2 \pi \int_{0}^{4 \pi / \omega} V^{2}(t) \mathrm{d} t}{\int_{0}^{4 \pi / \omega} \int_{0}^{2 \pi} \frac{V^{2}(t)}{\bar{e}(\zeta, t)} \psi(\zeta) \mathrm{d} \zeta \mathrm{d} t}\right)^{2}}
$$

$$
P V_{\mathrm{c}}\left(N^{i}, J_{\mathrm{r}}^{i}, \theta_{\text {ali }}^{i}\right)=\frac{\omega}{8 \pi^{2}} \int_{0}^{4 \pi / \omega} \int_{0}^{2 \pi} \overline{P V_{\mathrm{c}}}(\zeta, t) \mathrm{d} \zeta \mathrm{d} t
$$

Note:

In the present approach, film thicknesses and contact PV have been obtained from an EHL (elastohydrodynamic-lubrication) code, ACCEL, considering mixed lubrication conditions. The code has been developed at Université de Poitiers [7]. It is also possible to 
get these values from a hydrodynamic code "adapted" for the mixed lubrication.

Both matrices, $e_{\mathrm{pf}}$ and $P V \mathrm{c}$, are used to interpolate in a parabolic way the results for the running conditions which belong to the interval $\left[N_{\min }, N_{\max }, J_{\text {rmin }}, J_{\text {rmax }}\right.$, $\left.\theta_{\text {alimin }}, \theta_{\text {alimax }}\right]$. The obtained values are the input data of module " 2 ", dedicated to the estimation of heat transfers.

\subsection{Module "2" : heat generation and transfer module}

In this module, dedicated to the estimation of the thermal flows (in and out), several developments have been done:

- The transformation of contact $P V$ into heat and flow shear between shaft and bearing.

- The evaluation of the temperature of the oil having cooled the piston. This temperature is function of speed and engine load.

- The estimation of the additional flows brought by several geometrical irregularities.

\subsubsection{Heat flow in the oil}

Evaluating the amount of heat flow entering the solids is done by estimating the ratio of heat flow in a fluid used as lubricant in an adiabatic bearing and a bearing having the same heat transfer with the environment as the considered conrod. Consider the following ratio:

$$
\alpha_{\mathrm{cish}}=\frac{E_{\mathrm{st}}}{E_{\mathrm{ad}}}
$$

The following quantities $E_{\mathrm{i}}$ are deduced from the internal power of the fluid respectively in adiabatic and realistic condition [8].

$$
\begin{aligned}
E_{\mathrm{ad}} & =\int_{0}^{\mathrm{LF}} \rho\left(\theta_{\mathrm{ali}}\right) C \mathrm{p}_{\mathrm{h}} \frac{V}{2} e_{\mathrm{cis}}(x)\left(\theta_{\mathrm{ad}}(x)-\theta_{\mathrm{ali}}\right) \mathrm{d} x \\
E_{\mathrm{st}} & =\int_{0}^{\mathrm{LF}} \rho\left(\theta_{\mathrm{ali}}\right) C \mathrm{p}_{\mathrm{h}} \frac{V}{2} e_{\mathrm{cis}}(x)\left(\theta_{\mathrm{st}}(x)-\theta_{\mathrm{ali}}\right) \mathrm{d} x
\end{aligned}
$$

With $\theta_{\text {ad }}$ and $\theta_{\text {st }}$ solution, of the following equations for a $\left(N, J_{\mathrm{r}}, \theta_{\text {ali }}\right)$ given triplet:

$$
\begin{array}{r}
\mathrm{h}_{\mathrm{eq}}\left(\theta_{\mathrm{st}}(x)-\theta_{\mathrm{ali}}\right)+\rho\left(\theta_{\mathrm{ali}}\right) C \mathrm{p}_{\mathrm{h}} e_{\text {cis }}(x) \frac{V}{2} \frac{\partial \theta_{\mathrm{st}}}{\partial x} \\
=\mu\left(\theta_{\mathrm{st}}\right) \frac{V^{2}}{e_{\text {cis }}(x)} \\
\rho\left(\theta_{\text {ali }}\right) C \mathrm{p}_{\mathrm{h}} e_{\mathrm{cis}}(x) \frac{V}{2} \frac{\partial \theta_{\mathrm{ad}}}{\partial x}=\mu\left(\theta_{\mathrm{ad}}\right) \frac{V^{2}}{e_{\text {cis }}(x)}
\end{array}
$$

In the relations $(8)-(11)$ the variable $e_{\text {cis }}$ is defined by:

$$
\begin{aligned}
& e_{\mathrm{cis}}=J_{\mathrm{r}}\left(1+e_{\mathrm{xc}} \cos \left(\frac{2 x}{D}\right)\right) \\
& \varepsilon_{\mathrm{xc}}=\left(\frac{e_{\mathrm{pf}}}{J_{\mathrm{r}}}\right)
\end{aligned}
$$

with

$$
\rho(\theta)=\rho_{0}\left(1-\alpha_{\mathrm{h}}\left(\theta-\theta_{0}\right)\right) .
$$

Usually, the ratio $\alpha_{\text {cish }}$ rests within the $(0.1 \ldots 0.3)$ interval.

\subsubsection{Heat due to contact}

The transformation of the contact $P V$ multiplied by $\varphi$ in heat flow for the shaft and the bearing, called $\phi_{\mathrm{a}}$ and $\phi_{\mathrm{c}}$, is made accordingly to the relations (14)-(15). Considering the low Jaeger's number related to the microcontact area in mixed lubrication, the Vernotte and Charron relationship [9] for the heat flow partition is adopted:

$$
\begin{aligned}
\phi_{\mathrm{a}} & =\frac{b_{\mathrm{a}}}{b_{\mathrm{a}}+b_{\mathrm{c}}} \varphi\left(H_{\mathrm{c}}, \theta_{\mathrm{mel}}, \theta_{\mathrm{s}}\right) P V_{\mathrm{c}} \\
\phi_{\mathrm{c}} & =\frac{b_{\mathrm{c}}}{b_{\mathrm{a}}+b_{\mathrm{c}}} \varphi\left(H_{\mathrm{c}}, \theta_{\mathrm{mel}}, \theta_{\mathrm{s}}\right) P V_{\mathrm{c}}
\end{aligned}
$$

In the relationships (15) and (16) the friction coefficient is deduced from Kragelsky works [10] and is approximated by the relationship:

$$
\begin{aligned}
\varphi\left(H_{\mathrm{c}}, \theta_{\mathrm{mel}}, \theta_{\mathrm{s}}\right)= & \varphi_{0}+\frac{P_{\mathrm{c}}}{H_{\mathrm{c}}\left(1-c_{1} \frac{\theta_{\mathrm{s}}}{\theta_{\mathrm{mel}}}\right)} \\
& \times\left(c_{0} \frac{Y_{\mathrm{sh}}}{P_{\mathrm{c}}}\left(1-c_{1} \frac{\theta_{\mathrm{s}}}{\theta_{\mathrm{mel}}}\right)-\varphi_{0}\right)
\end{aligned}
$$

for $P_{\mathrm{c}}<\frac{H_{\mathrm{c}}}{4}$ and $\theta_{\mathrm{s}}<\frac{2 \theta_{\mathrm{mel}}}{3}$.

\subsubsection{Heat transfer}

Estimation of heat transfer coefficients $h_{\mathrm{a}}, h_{\mathrm{b}}$ respectively for crankshaft/oil and conrod/oil is done using semi-empirical relationships [11]:

$$
h_{\mathrm{a}} \text { or } h_{\mathrm{b}}=h_{0}\left(R_{\text {gir }} \omega\right)^{\beta} \operatorname{Pr}^{1 / 3}
$$

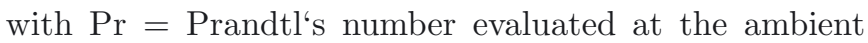
temperature.

$R_{\text {gir }}=$ gyration radius for crankshaft web or conrod.

These relationships have been obtained from a refined analysis. An estimation of heat transfer between the conrod faces, the crankshaft webs and the oil going out of the conrod is obtained from a more refined analysis [12]. In this analysis, is modeled the viscous flow between the faces of the conrod and the crankshaft webs under centrifugal effects. The consideration of flow outgoing of the conrod and the film thickness revealed, with respect to time, turbulence and flow discontinuities. After time averaging these flow variations, the evolution of the heat transfer coefficient for an arbitrary conrod geometry is calculated. The result is plotted in Figure 3, which shows the heat transfer coefficient between a side face of conrod of a $2 \mathrm{~L}$ turbodiesel engine and the oil exiting the bearing. These simulations have been performed with respect to speed and film thickness. 


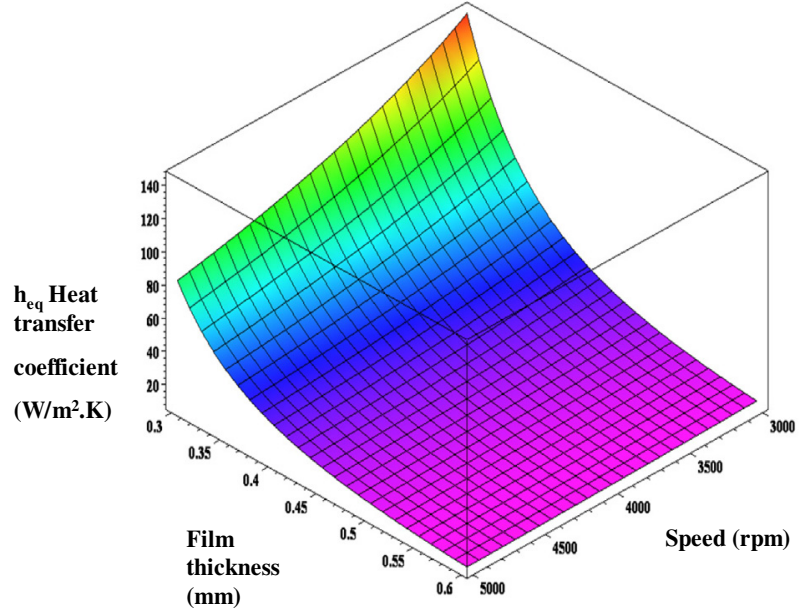

Fig. 3. Heat transfer coefficient for the lateral conrod faces.

\subsection{Temperature of the oil having cooled the piston}

As the oil pump flow is mostly a function of the speed and the temperature, the evolution of the pump pressure, noted $P_{\text {ali }}$, with respect to these two parameters is modeled with:

$$
P_{\text {ali }}\left(N, \theta_{\text {ali }}\right)=P_{0}\left(\theta_{\text {ali }}\right)+P_{1}\left(\theta_{\text {ali }}\right) N+P_{2}\left(\theta_{\text {ali }}\right) N^{2}
$$

The oil cooling the conrod and the crankshaft is heated by the piston to some extent. The piston temperature depends also on the engine load. To model the effect it is supposed that the thermal behavior of the piston, $\theta_{\text {pis }}$, is similar to the temperature of a simple lumped mass as it could be done with the nodal network methodology [13]. Then the temperature is approximated with the relationship:

$$
\begin{aligned}
M_{\mathrm{P}} C \mathrm{p} \frac{\partial \theta_{\mathrm{Pis}}}{\partial t}=k_{0}(N) P_{\mathrm{mot}} & +S_{\mathrm{Pis}} h_{\mathrm{Pis}}(N)\left(\theta_{\mathrm{Pis}}-\theta_{\text {ali }}\right) \\
+ & S_{\text {eau }} h_{\text {eau }}\left(\theta_{\mathrm{Pis}}-\theta_{\text {eau }}\right)
\end{aligned}
$$

The temperature increase of the oil, identified by $\theta_{\text {fpi }}$, coming from of the piston is obtained by solving Equation (19). The relationship is built by considering that the thermal flow evacuated by the oil going out of the jet equals the thermal flow evacuated by the oil cooling the piston [11]. The cooling heat flow of the piston is evaluated through thermal measurements.

$$
\theta_{\mathrm{fpi}}=\theta_{\mathrm{ali}}+\frac{h_{\mathrm{Pis}} S_{\mathrm{Pis}}}{\rho\left(\theta_{\mathrm{ali}}\right) C \operatorname{ph} \frac{\pi}{4} D_{\text {jet }}^{2} \xi_{\text {jet }} \sqrt{\frac{2 P_{\text {ali }}}{\rho\left(\theta_{\text {ali }}\right)}}}\left(\theta_{\mathrm{Pis}}-\theta_{\text {ali }}\right)
$$

\section{Note:}

In the previous heat transfer estimation, the heat flow in crankshaft drilling is neglected. Indeed, the crankshaft drilling length, $L$, is not sufficient for establishing a stable thermal profile in the oil flow.
This length does not verify the inequality:

$$
L>0.05 \mathrm{~d} R e_{\mathrm{d}} P r
$$

Consequently, considering reference [8], Nusselt's number follows the relationship proposed by Graetz:

$$
N u=a_{0} N_{\text {ref }} x^{-0.31}
$$

with $a_{0}=4.5$ for a tube with constant wall temperature. The average heat flow exchanged along the drilling will be:

$$
\overline{N u}=\frac{1}{L-L_{0}} \int_{L_{0}}^{L} N u(x) \mathrm{d} x
$$

In the case of a $2 \mathrm{~L}$ turbodiesel engine, it is obtained $\overline{N_{u}}=11.3$.

Then, the heat transfer coefficient for a $5 \mathrm{~mm}$ diameter drilling is:

$$
h_{\text {cond }}=\frac{\overline{N u}}{d} \lambda_{\text {oil }}=320 \text { W.m }{ }^{-2} \mathrm{~K}^{-1}
$$

Considering the heat transfer surface of the drilling and the small thermal difference between the oil temperature and the crankshaft temperature, it concludes that the heat flow is not important.

In addition to the previous items, we considered additional heat flows:

- the heat flow generated by ovality defects of the bearing housing;

- the geometrical defects which for some conrods with oblique cut can generate contacts with the crankshaft;

- the thermal contact resistance between the bearing and its housing. This resistance follows the relationship proposed by Yovanovich [14].

\subsection{Module “3": Nodal network module}

The nodal network [13] was built automatically complying with the overall size of various components. These dimensions are the bearing thickness, the crankpin diameter and width, and the crankshaft webs outer radius and width. Each component has several nodes of discretization as the oil film, the bearing where is differentiated the antifriction layer. Also, a thermal contact resistance between the bearing shell and its housing has been considered. The adopted discretization consists of 22 nodes.

With the discretization shown in Figure 4, the equations to be solved are found by writing the transient heat transfer. In these equations are taken into account thermal inertia, heat sources, and the heat transfer by conduction and convection.

$$
\left\{\begin{array}{l}
m_{i} C \mathrm{p}_{i} \frac{\partial \theta_{i}}{\partial t}=\phi_{i}+S_{i-1} \frac{\lambda_{i-1}}{e_{p i-1}}\left(\theta_{i}-\theta_{i-1}\right) \\
+S_{i} \frac{\lambda_{i}}{e_{p i}}\left(\theta_{i}-\theta_{i+1}\right)+S_{\text {exi }} h_{\text {exi }}\left(\theta_{i}-\theta_{\text {exi }}\right) \\
m_{i+1} C \mathrm{p}_{i+1} \frac{\partial \theta_{i+1}}{\partial t}=\phi_{i+1}+S_{i} \frac{\lambda_{i}}{e_{p i}}\left(\theta_{i+1}-\theta_{i}\right) \\
+S_{i+1} \frac{\lambda_{i+1}}{e_{p i+1}}\left(\theta_{i+1}-\theta_{i+2}\right)+S_{\text {exi }+1} h_{\text {exi }+1}\left(\theta_{i+1}-\theta_{\text {exi }}\right)
\end{array}\right.
$$




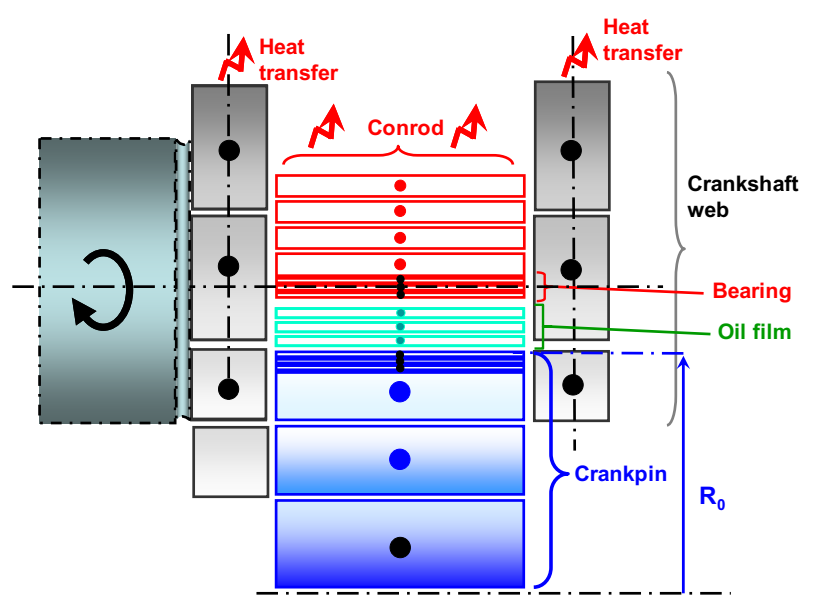

Fig. 4. Nodal discretization.

With the equations related to the piston temperature (19), the thermal flow shear (6), results a set of 25 differential equations required to be solved simultaneously. For simplicity, these equations have been approached using a specific software for symbolic and numerical calculation. Various modes of solving have been approached. Hence, either variations of in speed versus time, or clearance variations to check for the critical seizure clearance, have been performed. The seizure condition search consisted on identifying a thermal divergent situation, as it appears in Figure 5, and a condition that a temperature threshold should not be exceed. Numerically, the divergence is detected by analyzing the second order derivative of temperature and its variations.

\section{Results}

The following table defines the data set of operating parameters used for numerical analysis.

Considering numerical applications, in Figures 5 and 6 , are plotted two types of results. For Figure 5 the engine is stabilized for a while, and afterwards speeded from $3000 \mathrm{rpm}$ up to $6000 \mathrm{rpm}$. The evolution of the overall bearing temperature is plotted versus time. Remarkable fact, after the engine speed reaches $6000 \mathrm{rpm}$, the temperature increases slowly for a significant time until a sudden rise occurs. That is a bearing seizure. Obviously, the simulation is no more suitable at high temperature $\left(>250{ }^{\circ} \mathrm{C}\right)$ as the various models are not adequate for such condition.

In Figure 6, it is plotted the allowable minimum bearing clearance which lead to seizure. In this case, extra defects as non-circular geometries, joint faces step and roughness have been considered. All these defects were considered with their manufacturing tolerance. Some similar works have been done by Vogelpohl [15] establishing a relationship between sliding speed and relative clearance. Though the hypothesis on these investigations were different from the current (conrod loads) the trends are the same.
Table 1. Numerical data.

\begin{tabular}{|c|c|}
\hline Parameters & \\
\hline Max gaz pressure (MPa) & 18 \\
\hline Bore $(\mathrm{m})$ & 0.088 \\
\hline Stroke $(\mathrm{m})$ & 0.09 \\
\hline Piston mass (kg) & 0.917 \\
\hline Conrod mass (kg) & 0.892 \\
\hline Crank pin diameter $(\mathrm{m})$ & 0.069 \\
\hline Main bearing diameter $(\mathrm{m})$ & 0.072 \\
\hline Conrod width $(\mathrm{m})$ & 19.545 \\
\hline Conrod length (m) & 155.5 \\
\hline Conrod housing thickness (m) & 0.0083 \\
\hline Bearing thickness (m) & 0.0021 \\
\hline Crankshaft web width (m) & 0.0015 \\
\hline Oil viscosity at $100^{\circ} \mathrm{C}$ (Pa.s) & 0.019 \\
\hline Oil viscosity at $150{ }^{\circ} \mathrm{C}$ (Pa.s) & 0.0045 \\
\hline Nominal radial clearance $(\mu \mathrm{m})$ & 30 \\
\hline Oil $C \mathrm{p}_{\mathrm{c}}\left(\mathrm{J} \cdot(\mathrm{kg} \cdot \mathrm{K})^{-1}\right)$ at $100{ }^{\circ} \mathrm{C}$ & 2250 \\
\hline$\gamma_{\mathrm{oil}}\left(\mathrm{W} \cdot(\mathrm{m} \cdot \mathrm{K})^{-1}\right)$ & 0.14 \\
\hline$\alpha_{\mathrm{h}}\left({ }^{\circ} \mathrm{C}^{-1}\right)$ & $7 \times 10^{-4}$ \\
\hline$\theta_{0}\left({ }^{\circ} \mathrm{C}\right)$ & 15 \\
\hline$P_{0}\left(\mathrm{~kg} \cdot \mathrm{m}^{-3}\right)$ & 850 \\
\hline
\end{tabular}

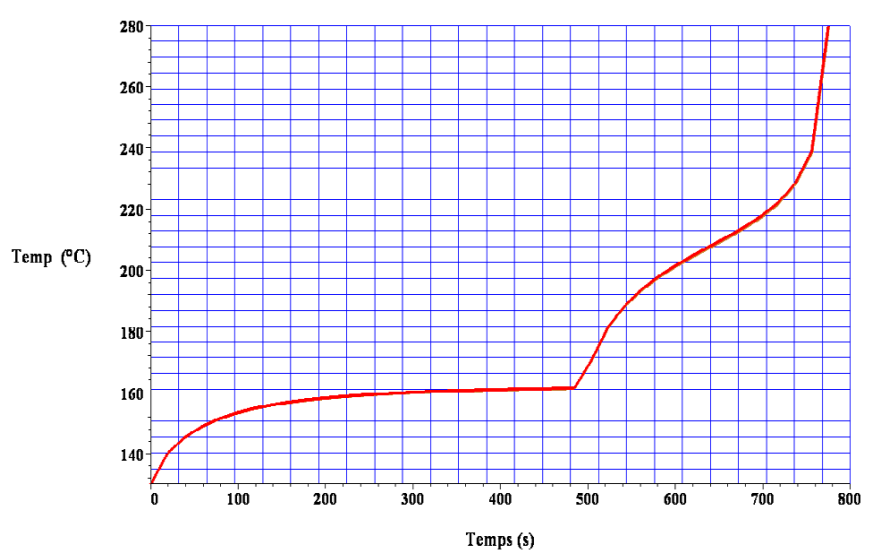

Fig. 5. Evolution of the bearing temperature.

After performing a comprehensive analysis, with the program previously described, for various configurations, the following comments can be drawn:

- for a too big clearance the seizure arises because of a too high value of contact $\mathrm{PV}$ and of the resulting modifications of the friction coefficient.

- for a too small clearance, the seizure is due to the thermal expansion as described in Figure 7.

The validity domain of this seizure tool is related to the performance of the modelling used to get the matrices of film thicknesses and of PV of contact.

\section{Conclusion}

The present approach models one of the seizure mechanisms by considering heat transfers around the crankshaft and the big end of the conrod. Heat sources 


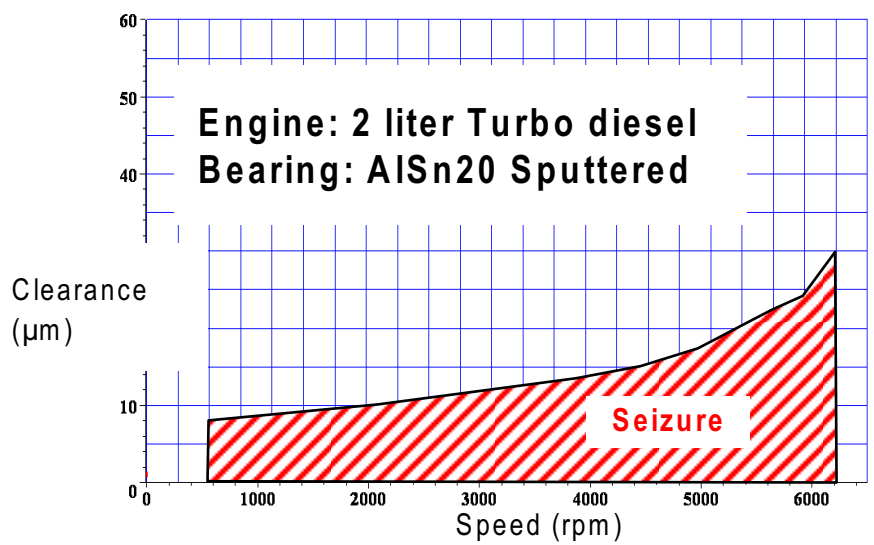

Fig. 6. Cartography of seizure.

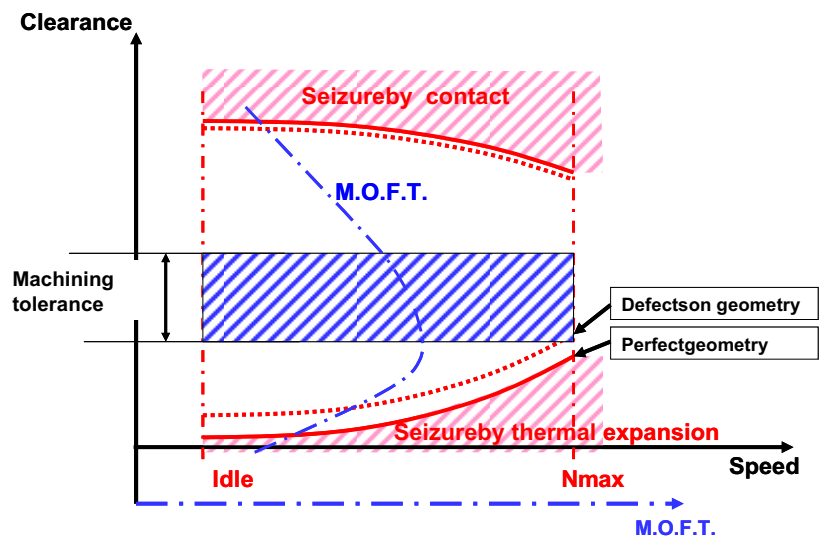

Fig. 7. Clearance and seizure.

in the bearing are due to oil shear and micro-contacts described by mixed lubrication models. The seizure mechanism is related to the thermal expansion difference between the conrod and the crankpin. The transient thermal behavior of the conrod bearing in defined approach is characterized by a simple set of equations, deduced from the nodal network technique. Then, these equations are solved thanks to a symbolic and symbolic-numeric computational software.

Despite the fact this approach is not a perfect thermoelasto-hydrodynamic modelling it has allowed to predict seizure on conrod bearing. This seizure model has been validated through experiments.

For engine design, the main interest of such a tool is:

- By knowing the overall bearing dimensions, the simulation robustness with respect to the seizure thanks due to the parametric model.
- The possibility to build iterations on several parameters such as fitting bearing stress, bearing clearance, non-circularity, roughness.

- The establishment of mapping for the minimum for seizure clearance according to the speed.

- The understanding of certain specific behaviors for bearing seizure.

- The understanding of main key factors of the seizure and the parameters to take into account in a "thermoelasto-hydrodynamic" model.

\section{References}

[1] D.M. Buzescu, M.D. Pascovici, Seizure of a high speed gas turbine bearing journal, Workshop bearing under severe operating conditions, EDF-LMS Futuroscope, 2006

[2] R.A. Burton, Heat, bearings and lubrication, Springer Publications, 2000

[3] P. Monmousseau, M. Fillon, Transient thermoelastohydrodynamic analysis for safe operating conditions of tilting-pad journal bearing during start-up, Trib. Int. 33 (2000) 225-231

[4] M.D. Pascovici, M.M. Khonsari, J.Y. Jang, On the modeling of the thermomechanical seizure, ASME J. Trib. 117 (2005) 744-747

[5] S.P. Timoshenko, J.N. Goodier, Theory of elasticity, McGraw-Hill portfolio Company, 3th edition, 1987

[6] A. Cameron, Basic Lubrication Theory, E. Horwood, 1976

[7] D. Bonneau, Lubrification EHD des paliers de moteurs thermiques, Laboratoire de mécanique des solides, UMR6610, Poitiers

[8] J.M. Latif, Heat Convection, Springer, 2006

[9] J.-J. Caubet, Théorie et pratique industrielle du frottement, Dunod Edition Technip, 1964

[10] I.V. Kragelsky, V.V. Alisin, Tribology lubrication, friction and wear, Tribology in Practice Series. Mir Publishers and Professional Engineering Publishing limited, 2001

[11] P. Arques, Conception et construction des moteurs alternatifs, Ellipses, 2000

[12] J.-L. Ligier, J.-P. Cadalen, Estimation des échanges thermiques entre l'huile, les faces des bras de vilebrequin et les faces latérales de bielle, Communication interne, 665542009-0129, 2009

[13] A. Alexandre, L. Tomaselli, Modélisation thermique des moteurs, outils numériques généraux, Ref.: BM2901, Techniques de l'Ingénieur, 2006

[14] M. Bahrami, J.R. Cuhlam, M.M. Yovanovich, Modeling thermal contact resistance: scale analysis approach, Trans. ASME, 126 (2004) 896-905

[15] G. Vogelpohl, Betriebsiche Gleitlager, Berechnungsverfaren fur Konstruktion und Betrieb, Springer, Berlin, 1958 